\title{
The mitigation of the progressive collapse of a 9-storey structure incorporating United States Department of Defence guidelines
}

\author{
M. Izadifar ${ }^{1}$, R. Naghshbandi ${ }^{1}$, R. Abadi $^{2}$ \& Ir. A. Ahmad ${ }^{1}$ \\ ${ }^{I}$ Faculty of Civil Engineering, Universiti Teknologi Malaysia, Malaysia \\ ${ }^{2}$ Faculty of Civil Engineering, Bauhaus University, Germany
}

\begin{abstract}
Many failures such as those due to blast, impact, wind pressure and earthquakes can be caused by the progressive collapse in structures. This paper will discuss different mitigation methods for progressive collapse corresponding numerical analysis for a 9-storey reinforced concrete structure by SAP2000 following severe initial damage. After removing specified critical columns the demand capacity ratio (DCR) of the members will be measured by the latest revision of Department of Defence of the United States (DOD) guideline, which is one of the most complete sets of criteria in terms of providing useful guidance to the designers in 2013. The structure has a potential of progressive collapse if DCR is more than 2 for symmetrical structure. Two approaches will be presented to diminish the potential of progressive collapse in the structures. They are adequate increase in the size of structural elements throughout the structure and establishing of bracing system at the top level. To gain the best method among all that have been presented for the mitigation of progressive collapse, providing Bracing at the top level is the most effective and economical method.

Keywords: blast, impact, wind pressure, earthquake, progressive collapse, demand capacity ratio.
\end{abstract}

\section{Introduction}

Progressive collapse is defined as "the spread of an initial local failure from element to element, resulting eventually in the collapse of an entire structure or a disproportionately large part of it" [1]. In other words, progressive collapse can 
be defined by a chain failure of structural members triggered by local failure or damage and causing partial or entire collapse of the structure [1]. The local failure or damage in well-engineered structures and buildings usually results from unanticipated abnormal loads. Most of the times these abnormal loads are caused by unusual events which are characterized by low probability of occurrence, short time effect and high intensity. Abnormal loads may include pressure loads (gas explosions and bomb blasts), impact loads (aircraft and vehicular collision and failing debris) and deformation loads (softening members resulting from fire and foundation subsidence) [1].

For many buildings, housing a large group of people, or which structures functions necessary to protect the public safety or occupancies that may be the subject of intentional sabotage or attack, more rigorous protection should be incorporated into designs. Recently, blast event whether accidental or as terrorist acts has increased and gained considerable attention by the structural designers. Requirements for blast resistant design and progressive collapse prevention are now mandatory in specific buildings like embassies, airports, emergency, management centers, and some critical governmental facilities which may be a target for terrorist attacks. For such buildings, more precautions should be considered in the design procedure.

The performance of buildings during a progressive collapse event depends on many factors. Those factors include: the actual strength to the design strength, the level of redundancy in the structural system, the level of structural integrity of the individual members to form a whole system, and the types of structural details and the ductility existing in the system.

In 1968 a gas explosion demolished a load-bearing wall, on the $18^{\text {th }}$ floor of Ronan Point apartment which consequently caused the collapse of one entire corner of this 22-storey building in New Ham (east London). This event was a milestone in structural engineering history and for the first time drew the attention of the research community and structural engineers towards the issue of progressive collapse. Indeed, the complete structural collapse of the twin towers of the World Trade Centre (WTC) in New York City on September 11, 2001, has significantly increased the concern about these phenomena and opened new view points for considering unexpected loadings in structural designs.

This paper will debate the influence of different mitigation methods for the progressive collapse of a 9-storey symmetrical reinforced concrete building, employing alternate path method (AP) incorporating linear static analysis according to the latest revision of department of defense (DOD) and ASCE 2010 guidelines.

\section{Design approaches for mitigating progressive collapse}

Generally, there are two major design approaches to lessen the potential of progressive collapse: direct design and indirect design. 


\subsection{Direct design approach}

In this approach explicit consideration of resistance to progressive collapse will be applied during analyses and design procedure. This approach includes two methods such as the specific local resistance (SLR) method and alternate load path (AP) method. The following subsections briefly review the two direct methods.

\subsubsection{The specific local resistance (SLR) method}

In this method, all members or a part of structure are designed and provided for to resist specific loads or threats as well as the normal design load. In the local resistance method, it is impossible to achieve an absolute resistance of any member to the unanticipated extraordinary event. Also, providing a large number of critical members with local resistance and/or obtaining very large sizes of the critical members make this method impractical in many applications [2].

\subsubsection{The Alternate Load Path (AP) method}

In this method the local failure is tolerated while the progressive collapse is prevented by providing alternate path to redistribute the residual loads to the other members. This method is used in analysis and design of new and existing building to resist potential progressive collapse. In addition, The Alternate Path method is used in two situations: 1) when a vertical structural element cannot provide the required tie strength, the designer may use the AP method to determine if the structure can bridge over the deficient element after it has been notionally removed, and 2) when the AP method must be applied for the removal of specific vertical load-bearing elements [3].

\subsection{Indirect design approaches}

In the indirect design, resistance of the structure against progressive collapse is implicitly gained in terms of integrity provisions through the design criteria considering the normal loading condition. The integrity of the structure is accomplished through the layout of the structural components, members sizing, connection details, minimum strength requirements and redundancy requirements in terms of continuity and ductility $[1,3,4]$.

The indirect design method is widely spread among engineers due to its easiness of implementation in different kinds of construction and simplicity as it is independent of abnormal loading condition. However, adopting this approach is limited to low level of protection against progressive collapse or to limited kinds of buildings as asserted in several design codes and standards [3] which require a direct design approach for the medium to high level of protection as well as for the critical buildings.

\section{Building characteristics}

The typical floor is plan of a 9-storey symmetrical reinforced concrete structure is shown in the figure 1 . The building has been analysed and designed by 
alternate path load (AP) method incorporating linear static analysis according to ACI318 [4]. Typical floor-to-floor height of the building is $3.5 \mathrm{~m}$ and first storey height is $4 \mathrm{~m}$. The size of all beam sections are kept $300 \times 400 \mathrm{~mm}$ the same over the height, and the sizes of column sections on the first, second, third, and fourth have been chosen $550 \times 550 \mathrm{~mm}$. The rest of column sections are considered 450 $\mathrm{x} 450 \mathrm{~mm}$. However, the lateral load is a significant parameter for the structure, this structure is assumed located in a zone where has no danger of critical lateral load exists. The primary loading considered on the building for this study are:

Gravity loading parameters:

-Dead load: self weight of the structural elements.

-Live load: on roof $1.5 \mathrm{kN} / \mathrm{m} 2$, on floors $3.0 \mathrm{kN} / \mathrm{m} 2$.

-Floor finish: $1.5 \mathrm{kN} / \mathrm{m} 2$, wall load: $7.13 \mathrm{kN} / \mathrm{m}$.

Material property data:

-Grade of steel fy: Fe415.

-Grade of concrete f'c: M35.

The modulus of elasticity of concrete Ec adopted in modified by the ACI code can be calculated by the formula given below:

$$
E c=4700 \sqrt{f^{\top} c}=27,805,000 \mathrm{MPa}
$$

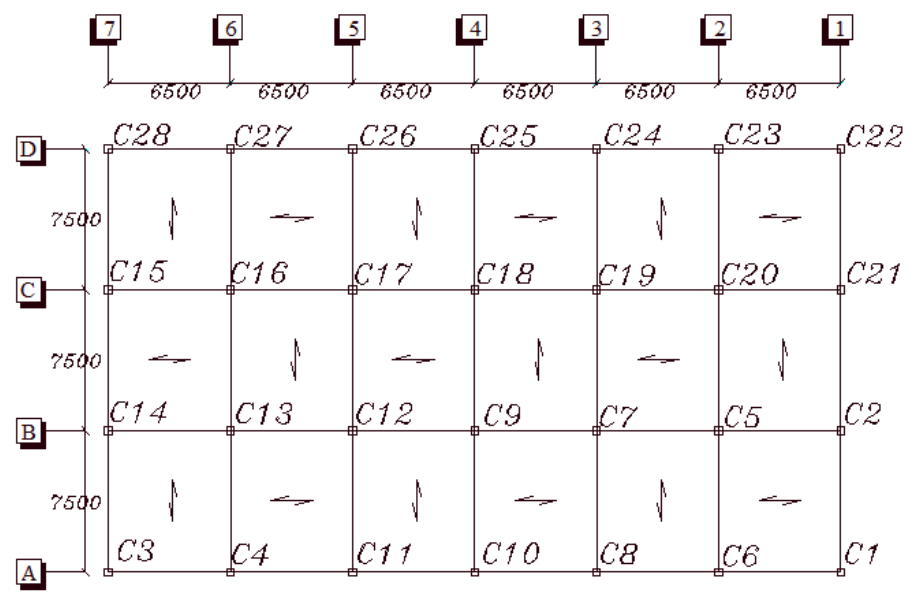

Figure 1: Typical floor plan of the building. 


\section{Analysis methodology}

Progressive collapse analysis of a 9-storey symmetrical concrete building is accomplished by following alternate load path (AP) method incorporating linear static analysis according to the latest revision of Department of Defence (DOD) and ASCE 2009 guidelines. Generally, original structure is designed for gravity and seismic loading using alternate load path (AP) method. Some criteria must be employed for analysis and design of structure to realize which columns have effects for progressive collapse after applying alternate load path (AP) method following below.

According to the Department of Defence (DOD) guideline, four critical levels are defined for both external and internal columns, which are:

1. First storey above foundation,

2. The storey directly under the roof,

3. Storey at mid-height,

4. Storey above the location which the size of the column changes.

The locations of critical external columns, relevant to each critical level mentioned above, according to alternate load path method, are: 1) external columns near the middle of the short side ( $\mathrm{C} 2$ on floors one, five and nine), 2) near the middle of the long side ( $\mathrm{C} 10$ on floors one, five and nine), 3) at the corner of the building ( $\mathrm{C} 3$ on floors one, five and nine), as shown in figure 2. On the other hand, removal of internal columns in the structure depends on uncontrolled public access. The locations of critical internal columns are: 1) internal columns near the middle of the short side, 2) near the middle of the long side, 3) at the corner of the uncontrolled space. Since the usage of the first floor in this study is taken account of a public parking, columns 9, 5 have just been removed on the first level, as shown in figure 2 .

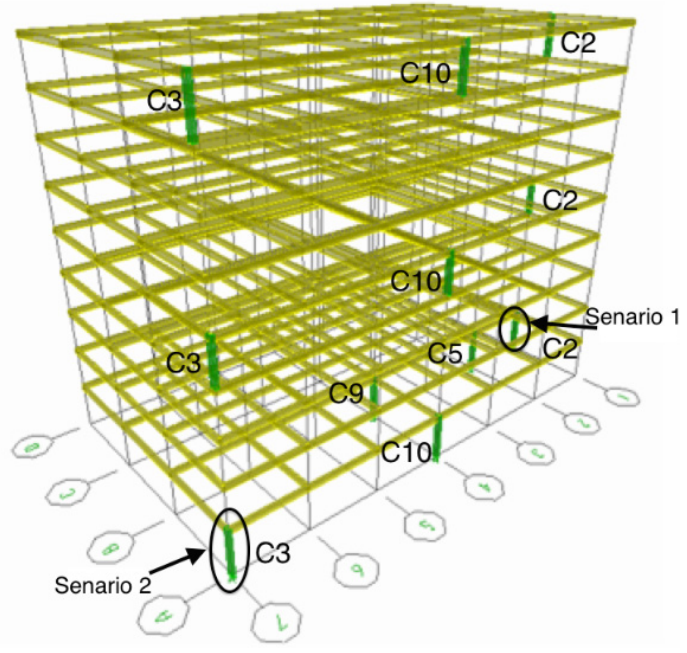

Figure 2: Locations of column removal for each scenario. 


\section{DOD linear static analysis procedure}

A non-linear procedure should be employed for those structures, which have more than 10 stories. Since, in this study 9-storey-building has been evaluated, linear static method was performed [5]. Based on DOD guidelines, the model was analysed with two load cases: 1) for calculating the deformation-controlled and 2) for calculating the force-controlled.

Load Case for Deformation-Controlled Actions QUD.

Increased Gravity Loads for Floor Areas Above Removed Column or Wall.

$$
G L D=\Omega L D[1.2 D+(0.5 L \text { or } 0.2 S)]
$$

Gravity Loads for Floor Areas Away From Removed Column or Wall.

$$
G=1.2 D+(0.5 \text { L or } 0.2 S)
$$

Load Case for Force-Controlled Actions QUF.

Increased Gravity Loads for Floor Areas Above Removed Column or Wall.

$$
G L F=\Omega L F[1.2 D+(0.5 L \text { or } 0.2 S)]
$$

Subsequently, from the above load cases, demand capacity ratio (DCR) of all members in each scenario has been assessed. If the DCR of a member in flexure exceeds 2 for symmetric configuration, the member is considered as failed. In shear and in axial loading acceptable DCR is 1 for symmetric and asymmetric structures [6]. The DCR of each member in alternate load path (AP) method is calculated from the following equation:

$$
D C R=\frac{Q_{U D}}{Q_{C E}}
$$

QUD = Acting force (demand) determined in member or connection.

QCE = Expected ultimate, un-factored capacity of the member and connection.

In this paper 11 critical scenarios have been studied. After considering all scenarios obviously observed that scenarios 1 and 2 have the most severe effects in the all elements of the structure. In scenario 1, column 2 has been removed, and the consequence of this action resulted the failure of columns through stories named 1, 2 as shown in figure 3 . In the same way in scenario 2, column 3 was removed and effects of this removal on the surrounding columns have been studied. Results are shown in the figure 4. 


\section{UFC LOADING}

Linear Static column $1 \quad$ Linear Static column 2

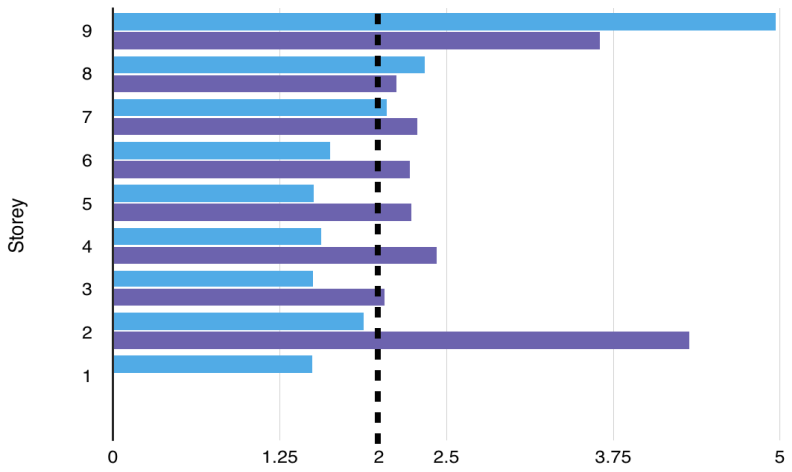

DCR

\begin{tabular}{|l|c|c|c|c|c|c|c|c|c|}
\hline & 1 & 2 & 3 & 4 & 5 & 6 & 7 & 8 & 9 \\
\hline LSiatic C 1 & 1.495 & 1.876 & 1.497 & 1.557 & 1.505 & 1.624 & 2.051 & 2.335 & 4.969 \\
\hline LS Siatic C 2 & - & 4.32 & 2.034 & 2.426 & 2.233 & 2.212 & 2.79 & 2.122 & 3.651 \\
\hline
\end{tabular}

Figure 3: DCR for columns after applying scenario 1.

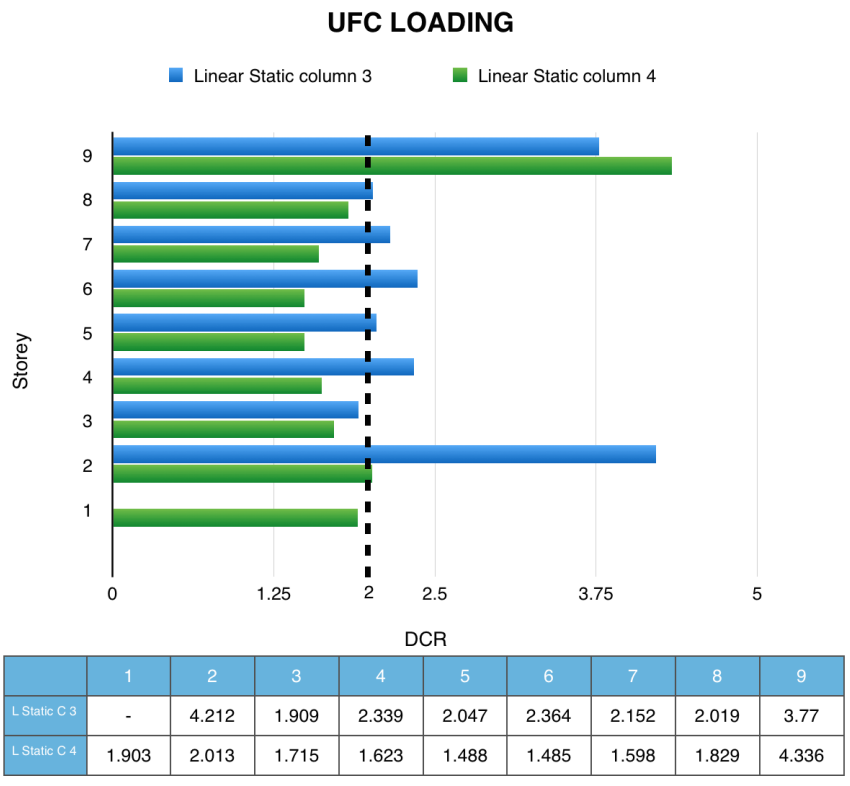

Figure 4: DCR for columns after applying scenario 2. 


\section{Methods to mitigate progressive collapse}

For those structures that have high potential for progressive collapse, it is really essential to diminish it [6]. Based on the Department of Defence guideline, if DCR of beams and columns exceed admissible value, the building is considered having high danger for progressive collapse. There are some significant changes to reduce the potential for progressive collapse like greatly increase of structural elements sizes, applying additional reinforcement and developing structural actions.

In this paper, two different methods will be presented to reduce the potential of progressive collapse of 9-storey symmetrical reinforced concrete structure. They are as follows:

Method 1: Establishing of bracing system at the top level.

Method 2: Adequate increase in the size of structural elements throughout the structure.

The original and modified sizes of structural members after applying mitigation methods are shown in table 1.

Table 1: Member sizes for 9-storey building for three proposed methods.

\begin{tabular}{|l|c|c|c|c|c|}
\hline \multirow{2}{*}{ Member } & Storey & \multicolumn{2}{|c|}{ Column $(\mathrm{mm})$} & \multirow{2}{*}{ Beam (mm) } & \multirow{2}{*}{ Brace } \\
\cline { 3 - 4 } & & Int & Ext & & \\
\hline \multirow{2}{*}{ Original Size } & $1,2,3,4$ & $550 \times 550$ & $450 \times 450$ & \multirow{2}{*}{$300 \times 400$} & \\
\cline { 2 - 4 } & $5,6,7,8,9$ & $450 \times 450$ & $450 \times 450$ & & \\
\hline \multirow{2}{*}{ Method 1 } & $1,2,3,4$ & $550 \times 550$ & $450 \times 450$ & $300 \times 400$ & 2 UNP80 \\
\cline { 2 - 4 } & $5,6,7,8,9$ & $450 \times 450$ & $450 \times 450$ & & \\
\hline Method 2 & All & $600 \times 600$ & $600 \times 600$ & $450 \times 600$ & ---- \\
\hline
\end{tabular}

\section{Analysis results}

The DCR has been calculated for 2 of the most critical scenarios by UFC linear static load case. For scenario 1, external column located in the near middle of short length on the first level is removed (C8) and the DCR of the column 1 and 2 in the all stories have been analysed again for two recommendation methods. The results, before and after applying 2 mitigation methods are extracted and shown in figure 5 and 6. Similarly, external column placed on the corner of the first level is removed for scenario 2 and DCR of columns 3 and 4 have been analysed as well as scenario 1 . The results are respectively shown in the figure 7 and 8 .

After removing the columns 2 and 3 the displacement at the points above the removed columns in all stories have been studied. The results for after and before applying the mitigation methods are provided in figure 9. As it can be seen the vertical displacement in column removal points are considerably decreased. These results can clarify, to what extend these approaches were effective. 
UFC LOADING (METHOD 1)

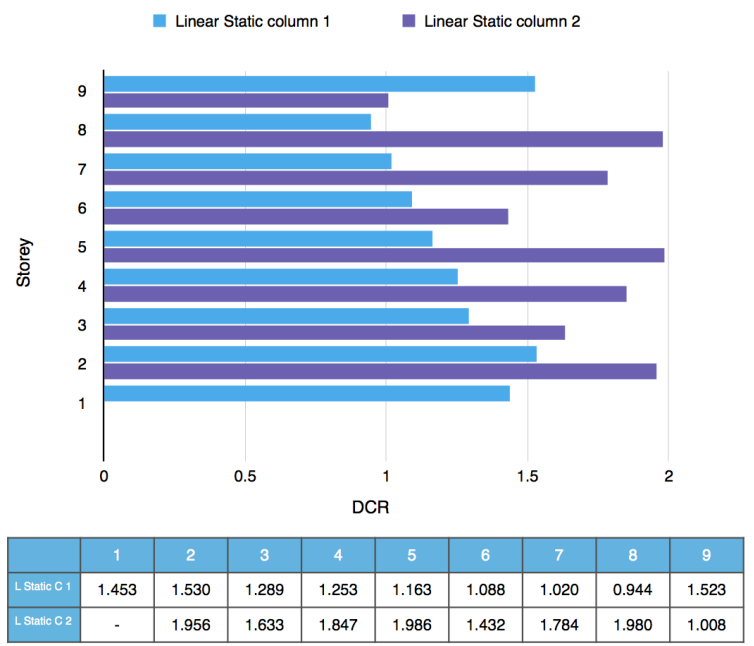

Figure 5: DCR for columns 1 and 2 after applying mitigation method 1 .

\section{UFC LOADING (METHOD 2)}

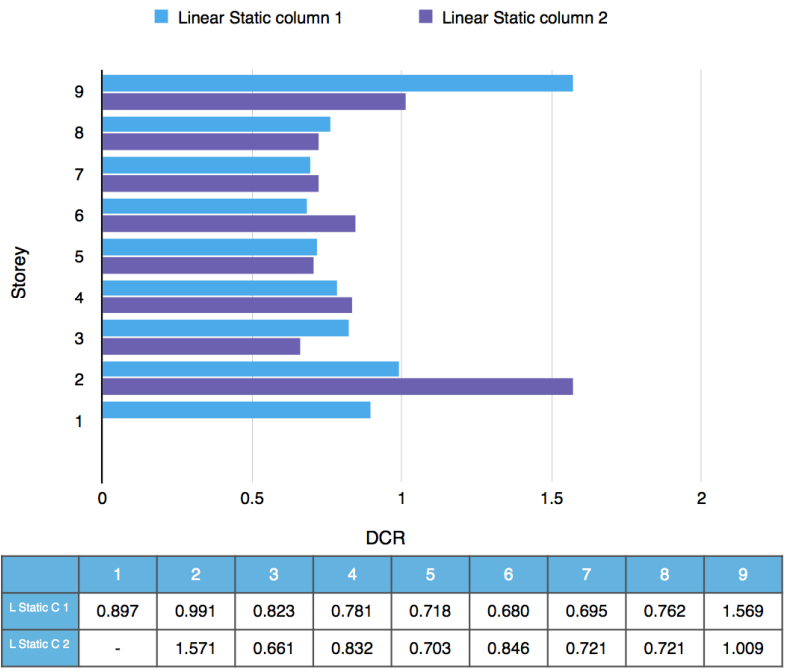

Figure 6: DCR for columns 1 and 2 after applying mitigation method 2. 
172 High Performance and Optimum Design of Structures and Materials

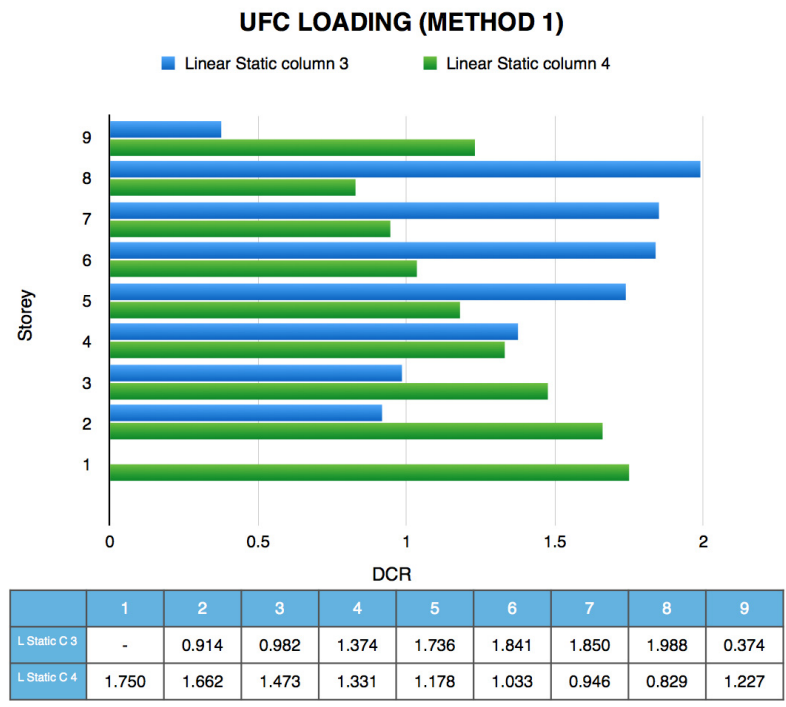

Figure 7: DCR for columns 3 and 4 after applying mitigation method 1 .

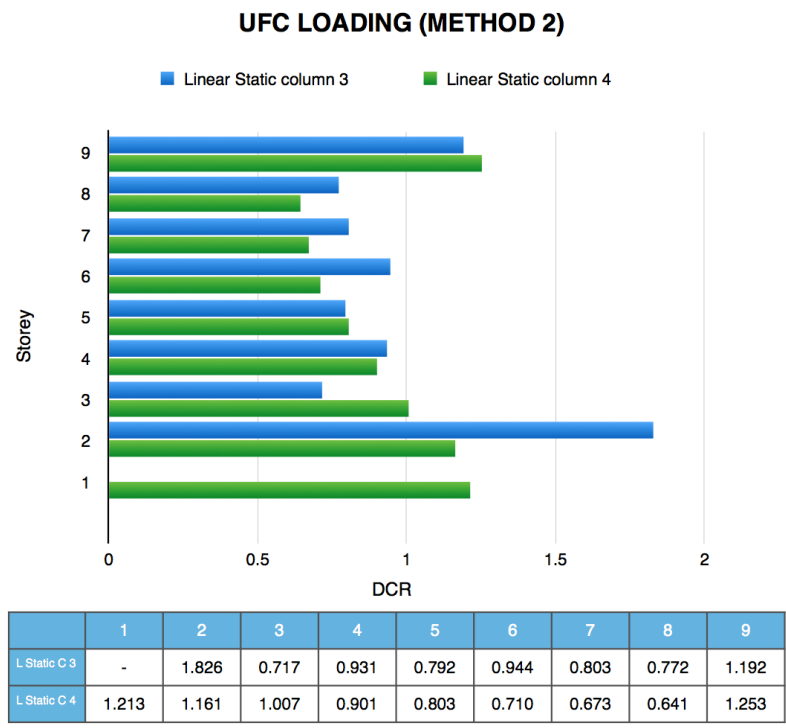

Figure 8: DCR for columns 3 and 4 after applying mitigation method 2. 

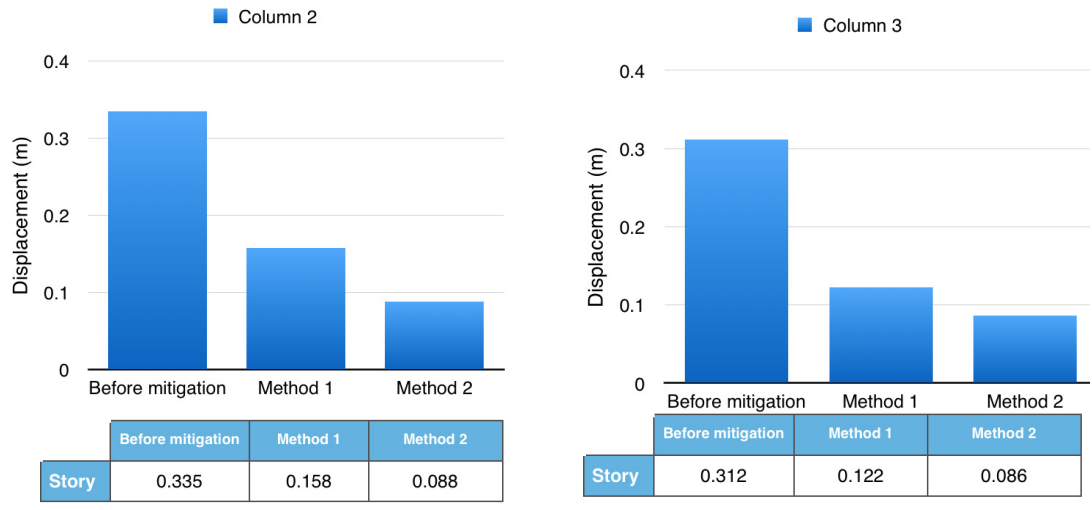

Figure 9: Displacement at columns 2, 3 removal point before and after mitigation.

\section{Conclusion}

In this paper, a 9-storey symmetrical RC building has been studied according to DOD guideline by liner static analysis. This structure has been modelled by SAP2000 and 11 scenarios were considered to gain which scenario had the worst effect in the structure. Among all defined scenarios, removing of the columns near the middle of short length and also the column on the corner of building on the first level have had the most destructive impact in the structure. After removing these two critical columns DCR value of some columns throughout the stories exceeded the allowable limit. For decreasing the potential of the progressive collapse 2 mitigation methods were applied and among these methods, providing bracing system in the last storey was the best approach in terms of structural response and also economical aspect.

\section{References}

[1] A. S. O. C. Engineers, ASCE/SEI 7-10, American Society of Civil Engineers, 2010.

[2] B. R. \&. L. E. V. Ellingwood, "Approaches for Design against Progressive Collapse,” Journal of Structural, Division 104 (ST3): pp. 413-423, 1978.

[3] Department of Defence (DOD), Unified Facilities Criteria (UfC) - Design of Buildings to Resist Progressive Collapse, 2013.

[4] A. C. Institute, Building Code Requirements for Structural Concrete (ACI 318), 2011.

[5] S. W. K. A. R. MacNeill, "Methodologies for Progressive Collapse Analysis," ASCE, pp. 1126-1135, 2009.

[6] P. V. P. A. D. D. Joshi, "Various Approaches for Mitigating Progressive Collapse of Asymmetrical RC," ASCE, pp. 2084-2094, 2012. 